\title{
Intellectual performance in children after circulatory arrest with profound hypothermia in infancy
}

\author{
D. F. DICKINSON AND J. E. SAMBROOKS
}

Royal Liverpool Children's Hospital

SUMMARY 38 children were assessed 22 months to 6 years after open heart surgery using circulatory arrest with deep hypothermia. The mean IQ of the group was $99 \cdot 2$ (SD 19.5). No correlation was found between IQ and the age or weight at operation or the duration of circulatory arrest. The results suggest that the technique gives effective protection to the brain during periods of circulatory arrest for up to 60 minutes.

Surgical treatment in early infancy is sometimes necessary in children with congenital heart disease either because of intractable cardiac failure or arterial hypoxia. The combined mortality from early palliation followed by later total correction led to attempts at complete correction as a primary procedure. However, early experience with standard cardiopulmonary bypass in infancy was associated with major problems in most centres (Baffes, 1968; Ching et al., 1971; Hallman and Cooley, 1971) and although cardiopulmonary bypass has now successfully been used (Sugimura and Starr, 1977), many centres continue to use deep hypothermia with circulatory arrest for these patients. The technique offers the surgeon almost ideal operating conditions in an empty, still, and bloodless heart and several successful series of complete repairs of complex malformations have been reported (Mori et al., 1972; Barratt-Boyes, 1973; Venugopal et al., 1973).

The vulnerability of the developing brain to a number of insults has been well documented (Dobbing, 1974) and concern has existed regarding the long-term intellectual development of children subjected to periods of circulatory arrest in infancy. Although reports of neurological damage (Bjork and Hultquist, 1962) severely curtailed the use of deep hypothermia in the early 1960s, the incidence of serious neurological complications in the infants reported by Mori et al. (1972) was low, and subsequent reports havesuggested that in the longer term, intellectual function remains within the normal range in most cases (Brunberg et al., 1974; Stevenson

Cardiac Unit, Royal Liverpool Children's Hospital

D. F. DICKINSON, senior registrar

J. E. SAMBROOKs, senior clinical psychologist et al., 1974; Messmer et al., 1976; Haka-Ikse et al., 1978). Nevertheless, in each series abnormal neurological behaviour in the immediate postoperative period and later intellectual retardation was seen in a significant number of patients and further evaluation of the technique is needed.

\section{Patients and methods}

Between January 1971 and December 1975, 84 children underwent surgical correction of congenital heart disease at the Royal Liverpool Children's Hospital using deep hypothermia (core cooling) with circulatory arrest. During the period this technique was used, with few exceptions, for all children requiring open heart surgery at $<2$ years of age, or below $10 \mathrm{~kg}$ in weight. There were 29 deaths in hospital and one death later. One child has been lost to follow-up. Four children subsequently required a 2nd operation which was carried out under hypothermic conditions in 3 and using standard cardiopulmonary bypass in the 4th.

Assessment of intellectual ability was made by one of us (J.E.S.) in $\mathbf{3 8}$ of the $\mathbf{5 4}$ long-term survivors, 22 months to 6 years after operation. At the time of testing, the ages of the children ranged from 28 to 105 months (median 50). The children were those attending the hospital for a routine outpatient visit during 1976 and 1977 and those living in the immediate vicinity of Liverpool. No child was excluded because of a neurological abnormality noted before the operation. An informal interview with the parent(s) was followed by assessment of the child on one of four tests selected according to the age and ability of the child. The Wechsler preschool and primary scale of intelligence or the Wechsler 


\section{Dickinson and Sambrooks}

intelligence scale for children was used in 14 children and the Merrill Palmer scale of mental tests in 23. One severely handicapped child was assessed using the Griffiths developmental scale. In addition, all the children were assessed on the Vineland scale of social maturity.

The cardiac lesions of the tested children are given in Table 1. At time of operation the median age of the children was 9 months (range 5 days to 36 months), the mean weight $6 \cdot 5 \mathrm{~kg}$ (range $2 \cdot 4$ to $12 \cdot 3$ ), and the mean duration of circulatory arrest $47 \mathrm{~min}$ (range 20 to 69). Hypothermia from 14 to $25^{\circ} \mathrm{C}$ (nasopharyngeal) was used, most children being arrested at 18 or $19^{\circ} \mathrm{C}$. In these respects there were no significant differences between the tested group, the group of survivors as a whole, or the 29 children who did not survive.

Surgical technique. The surgical technique was described in detail previously (Hamilton et al., 1973).

After induction of anaesthesia, lines for the continuous monitoring of arterial and central venous pressure are established. The electrocardiograph, nasopharyngeal, and oesophageal temperatures are also monitored continuously during the procedure. Cardiopulmonary bypass is established using a single right atrial cannula with pump return to the ascending aorta. A period of perfusion at $2.41 / \mathrm{m}^{2}$ with the Temptrol infant model oxygenator (Bentley Laboratories Inc., USA) in conjunction with an infant heat exchanger, is used to maintain the rate of cooling between 0.5 and $1.0^{\circ} \mathrm{C} / \mathrm{min}$. After reaching a predetermined low temperature (usually $18^{\circ} \mathrm{C}$ ) perfusion is continued for a further 5 minutes to allow for temperature equilibration within the body. The infant is then exsanguinated through the venous line, snares are applied to the venae cavae, and a single clamp is applied to the aorta and pulmonary artery to lessen the risk of air embolism. After repair of the cardiac lesion is complete, perfusion is reestablished and rewarming is begun. Acidosis is corrected at $32^{\circ} \mathrm{C}$ and inotropic drugs used if necessary to support the circulation.

\section{Results}

The mean IQ of the 38 tested children was 99.2

\section{Table 1 Cardiac lesions of tested children}

Transposition of great vessels

Ventricular septal defect

Total anomalous pulmonary venous drainage

Fallot's tetralogy

Pulmonary stenosis

Common atrioventricular canal

Aortic pulmonary window
(SD 19.5). On the Vineland scale of social maturity the mean score was 112 (SD 19). There was no significant difference in mean IQ between those patients tested using the Merrill Palmer scale of mental tests, and those tested using either the Wechsler intelligence scale for children or the Wechsler preschool and primary scale of intelligence. Although the number of patients in some groups is small, no statistically significant correlation was found between IQ and age at operation (Fig. 1), weight at operation (Fig. 2), and duration of circulatory arrest (Fig. 3). Children with cyanotic congenital cardiac lesions (mean IQ 99) did not score significantly lower than those with acyanotic lesions (mean IQ 99.7), and there was no significant

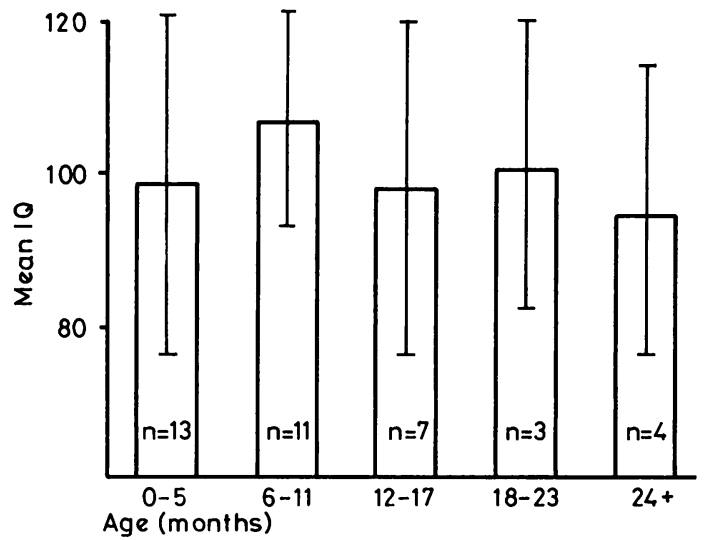

Brackets indicate \pm 1 SD.

Fig. 1 Mean IQ plotted against age at operation.

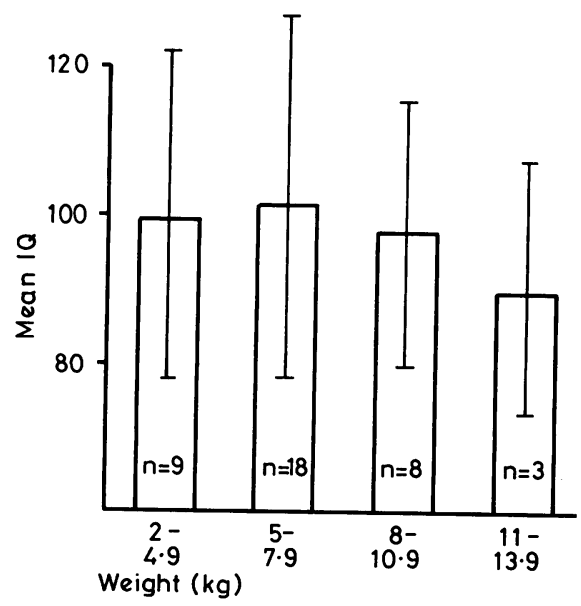

Brackets indicate \pm 1 SD.

Fig. 2 Mean IQ plotted against weight at operation. 
difference in mean IQ between the four main diagnostic categories (Fig. 4).

Seven $(18 \%)$ children had IQ scores of at least 1 SD below the mean of the test (Table 2). Three were patients known to have neurological abnormalities dating from before the time of operation. Low cardiac output, with convulsions on the 4th postoperative day may have contributed to brain damage in one child, and one child (Case 6, Table 2) underwent 2 operations at an age at which we would now consider this technique to be inappropriate. A 6th child was uncooperative during testing. She attends a normal primary school and may well come within the normal range on retesting. No satisfactory explanation for retardation was found in the 7 th

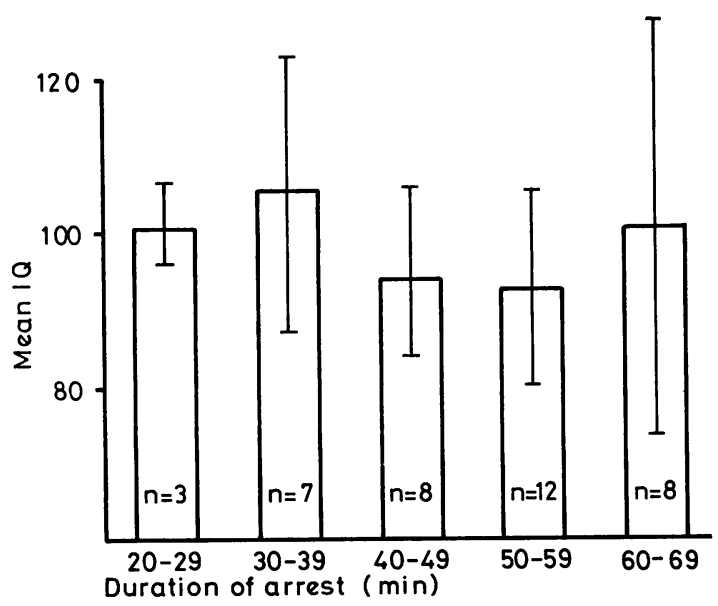

Brackets indicate $\pm 1 \mathrm{SD}$.

Fig. 3 Mean IQ plotted against duration of circulatory arrest.

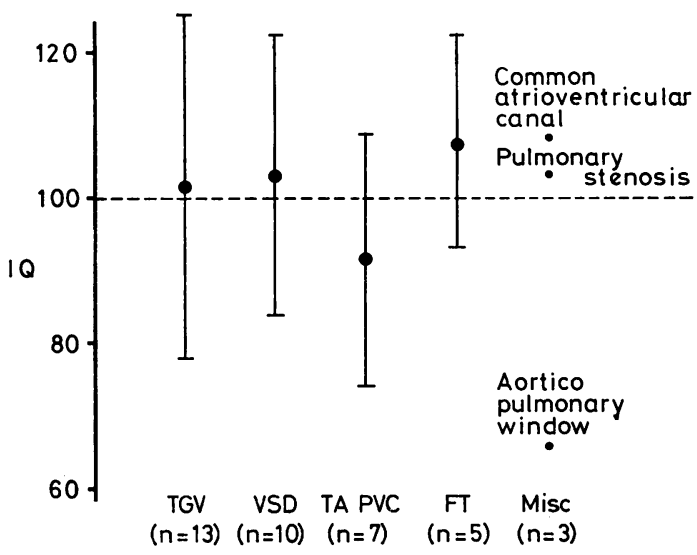

Brackets indicate \pm 1 SD.

TGV Transposition of great vessels

VSD Ventricular septal defect

TAPVC Total anomalous pulmonary venous connection

FT Fallot's tetralogy

Fig. $4 I Q$ in relation to type of cardiac defect

child. One other child developed abnormal neurological signs in the postoperative period, but now has an IQ of 86 and a social quotient of 105 and attends a normal school.

Most children assessed using Wechsler tests showed good correlation between verbal and performance scores. In 3 children however, an abnormal discrepancy was present, the performance score being significantly higher in 2 and the verbal score higher in the 3 rd.

\section{Discussion}

The results of experiments in laboratory animals have shown that oxygen consumption and cerebral

Table 2 Operation details of children scoring 1 SD below the test mean

\begin{tabular}{|c|c|c|c|c|c|c|c|}
\hline \multirow[t]{2}{*}{ Case no. } & \multirow{2}{*}{$\begin{array}{l}\text { Cardiac } \\
\text { lesion }\end{array}$} & \multicolumn{2}{|l|}{ At operation } & \multirow{2}{*}{$\begin{array}{l}\text { Duration of } \\
\text { arrest (min) }\end{array}$} & \multirow{2}{*}{$\begin{array}{l}\text { Temperature } \\
\text { of arrest } \\
\left({ }^{\circ} \mathrm{C}\right)\end{array}$} & \multirow[t]{2}{*}{$I Q$} & \multirow[t]{2}{*}{ Comments } \\
\hline & & Age (months) & Weight $(k g)$ & & & & \\
\hline 1 & TGV & 3 & $5 \cdot 0$ & 69 & 15 & 52 & $\begin{array}{l}\text { Cardiac arrest during catheterisation. } \\
\text { Convulsions before and after operation. }\end{array}$ \\
\hline 2 & TAPVD & 1 & $2 \cdot 7$ & 50 & 20 & 76 & $\begin{array}{l}\text { Klippel Feil syndrome. Cardiac arrest in } \\
\text { first month of life. Hypertonic before } \\
\text { operation. }\end{array}$ \\
\hline 3 & APW & 2 & $2 \cdot 4$ & 50 & 25 & 65 & $\begin{array}{l}\text { Breech delivery. Severe birth asphyxia. } \\
\text { Convulsions before operation. } \\
\text { Hypertonic before operation. }\end{array}$ \\
\hline 4 & TGV & 25 & $7 \cdot 9$ & 63 & 18 & 76 & Uncooperative during testing. \\
\hline 5 & VSD & 13 & $7 \cdot 4$ & 57 & 18 & 62 & \\
\hline 6 & TGV & $34(36)$ & $11 \cdot 3(11 \cdot 5)$ & $57(37)$ & $19(18)$ & 74 & $\begin{array}{l}\text { Reoperation for pulmonary venous } \\
\text { obstruction. }\end{array}$ \\
\hline 7 & TAPVD & 10 & $8 \cdot 0$ & 33 & 16 & 76 & $\begin{array}{l}\text { Low cardiac output syndrome for } 48 \text { hours } \\
\text { after operation. Convulsions at } 4 \text { days } \\
\text { after operation. }\end{array}$ \\
\hline
\end{tabular}

TGV = transposition of great vessels; VSD = ventricular septal defect; TAPVD = total anomalous pulmonary venous drainage; $\mathbf{A P W}=$ aortico pulmonary window. 
metabolic rate decrease at between 6 and $15 \% /{ }^{\circ} \mathrm{C}$ fall in brain temperature (Rosomoff and Holladay, 1954; Hägerdal et al., 1975). Within the range of hypothermia usually used in cardiac surgery at present, the relationship between cerebral oxygen consumption and temperature is probably linear. With this information, the safe period of circulatory arrest at between 16 and $19^{\circ} \mathrm{C}$ has been extended to between 60 and $75 \mathrm{~min}$ (Barratt-Boyes, 1973) and arrest periods of up to $120 \mathrm{~min}$ at $10^{\circ} \mathrm{C}$ have been reported (Belsey et al., 1968). The possibility of neurological damage or intellectual impairment resulting from prolonged circulatory arrest or deep hypothermia has been appreciated for many years. Bjork and Hultquist (1952) reported 5 cases of fatal brain damage in children after hypothermic circulatory arrest. Histologic study of the brains in these patients showed a reduction in the number of ganglion cells in the globus pallidum with similar changes in the parietal cortex, hippocampus, and thalamus. Refinements in technique led by the University of Washington (Mohri et al., 1969) and the University of Kyoto (Hikasa et al., 1967) have enabled surgeons to operate safely in small infants with few major neurological complications.

Most centres have favoured the use of surface cooling to induce hypothermia, but metabolic studies of both surface-cooled and core-cooled patients have failed to establish conclusively the superiority of either technique (Harris, 1973). The advantages of core rewarming are widely accepted (Mori et al., 1972; Barratt-Boyes et al., 1973). Since 1970 we have used a technique of core cooling and core rewarming with a low incidence of cerebral problems. Although the mortality in the earliest years of the period was high, during 1973-77 the mortality rate was $22 \%$ in 102 patients under one year of age (Di Eusanio et al., 1979).

Our results show no significant difference between the mean IQ of the survivors of hypothermic circulatory arrest and the mean of the normal population. The results compare favourably with the mean IQ previously reported in children with congenital heart disease who had not undergone corrective surgery (Linde et al., 1967; Silbert et al., 1969). Similar results have also been reported in a group of children who underwent corrective surgery at $<2$ years using conventional cardiopulmonary bypass (Sunderland et al., 1973). Although these results are encouraging, in our series the range of intelligence within the tested group shows a wider dispersion about the mean than would be expected in a normal population, and a significant proportion of the survivors showed evidence of intellectual retardation. However, in 3 children, there was clear evidence before operation of neurological dysfunction of sufficient severity to explain their present disability (Table 2). If these patients are excluded the mean IQ of the group is $102(S D+17)$ and does not differ significantly from the distribution of intelligence within the normal population.

Laboratory studies of many animal species have shown that the immature animal is more tolerant of the effects of acute hypoxia than the adult (Dawes, 1968). In man, brain growth is known to continue to age 18 months (Dobbing, 1974) and the neonate might therefore be expected to show greater tolerance to a given period of circulatory arrest than the more mature child. The possibility that increasing age at the time of operation might be associated with a lower rate IQ score was suggested by Messmer $e t$ al. (1976). Our results show a similar tendency but the number of children $>$ age 18 months at the time of operation is small and the correlation is not statistically significant. Nevertheless, the occurrence of mental retardation in 2 of the 4 patients who underwent operation at $>2$ years of age suggests that particular caution is needed if the technique is to be used at this age. Our current policy (Di Eusanio et al., 1979) is to use this technique only in a few selected cases at age $>12$ months.

Neurological sequelae after circulatory arrest with hypothermia include convulsions, paresis, hypotonia, rigidity, choreoathetosis, alteration of consciousness or personality, and impairment of intellect (Björk and Hultquist, 1962; Mohri et al., 1969; Mori et al., 1972; Venugopal et al., 1973; Brunberg et al., 1974). Similar complications have been described after operation using conventional cardiopulmonary bypass (Gilman, 1965; Javid et al., 1969). Many factors may be responsible for such neurological damage. Cardiopulmonary bypass, used both for cooling and rewarming may be complicated by embolisation of gas, fat, or fibrin-platelet aggregates (Aguilar et al., 1971). Regional impairment of cerebral microvascular perfusion has been shown in experimental animals during core cooling and rewarming, and may be a factor in creating uneven cerebral cooling (Aoyagi et al., 1975). Rapid core cooling may allow excessive temperature gradients to develop between blood and cerebral tissue and we take considerable care to control the rate of cooling (Di Eusanio et al., 1979). Since cerebral blood flow is influenced by changes in arterial $\mathrm{PcO}_{2}$ (Lassen, 1974), carbon dioxide concentrations of $10 \%$ are used in the inspired gas mixture below $30^{\circ} \mathrm{C}$ to promote cerebral vasodilatation during cooling. Accumulation of cerebral metabolites during prolonged circulatory arrest could also be a factor in the production of postoperative cerebral damage. However, if this were the case, it might be expected that longer periods of arrest would be associated with poorer 
intellectual function in the survivors. Our results do not support this conclusion, and suggest that the technique gives effective protection to the brain for periods of up to $60 \mathrm{~min}$ of circulatory arrest, and possibly for up to $70 \mathrm{~min}$.

Previous authors (Linde et al., 1967; Silbert et al., 1969) have noted the tendency for older children with cyanotic congenital heart disease to have significantly lower IQ scores than children with acyanotic congenital heart disease. From their results, Silbert et al. (1969) came to the tentative conclusion that chronic hypoxia in the first 2 years of life might, by itself, have direct adverse effects on sensorimotor development, irrespective of any effect resulting from the reduced exercise tolerance of the cyanotic child. Linde et al. (1967), on the other hand, suggested that physical incapacity in the young child with cyanosis was the most important factor in the observed lower scores, and that this deficit in gross motor performance might result in an underestimation of the potential intellectual performance at a later age. In the present series defects were corrected, in all but 4 cases, before age 2 years and no significant difference in IQ was seen between the two groups. The possibility of psychological benefit resulting from early correction, although unlikely ever to be a major consideration in the timing of surgery, should not be discounted.

Detailed developmental assessment was not performed before operation and, indeed, many of the patients were sufficiently ill at that time for such testing to be of doubtful predictive value. We were unable therefore to use the patients as their own controls. Nevertheless, the distribution of intelligence within the tested group closely resembles that of the normal population, and suggests that the technique is effective in protecting the brain during prolonged periods of circulatory arrest.

We thank Mrs C. Smallman for technical assistance, Miss S. J. McIlrath for secretarial help, and Professor F. Harris for his help and advice.

This study was supported by a grant from the Mersey Regional Health Authority.

\section{References}

Aguilar, M. J., Gerbode, F., and Hil!, J. D. (1971). Neuropathic complications of cardiac surgery. Journal of Thoracic and Cardiovascular Surgery, 61, 676-685.

Aoyagi, M., Flasterstein, A. H., Barnette, J., Von Koch, L., Ross, J. N., Jr, and Kennedy, J. H. (1975). Cerebral effects of profound hypothermia $\left(18^{\circ} \mathrm{C}\right)$ and circulatory arrest. Circulation, 51 and 52, Supplement 1, 52-60.

Baffes, T. G. (1968). Total body perfusion in infants and small children for open heart surgery. Journal of Pediatric Surgery, 3, 551-560.
Barratt-Boyes, B. G. (1973). Complete correction of cardiovascular malformations in the first two years of life using profound hypothermia. In Heart Disease in Infancy, pp. 25-36. Edited by B. G. Barratt-Boyes, J. M. Neutze, and E. A. Harris. Churchill Livingstone: Edinburgh.

Belsey, R. H. R., Dowlatshahi, K., Keen, G., and Skinner, D. B. (1968). Profound hypothermia in cardiac surgery. Journal of Thoracic and Cardiovascular Surgery, 56, 497-509.

Björk, V. O., and Hultquist, G. (1962). Contraindications to profound hypothermia in open heart surgery. Journal of Thoracic and Cardiovascular Surgery, 44, 1-13.

Brunberg, J. A., Reilly, E. L., and Doty, D. B. (1974). Central nervous system consequences in infants of cardiac surgery using deep hypothermia and circulatory arrest. Circulation, 49 and 50, Supplement 2, 60-69.

Ching, E., DuShane, J. W., McGoon, D. C., and Danielson, G. K. (1971). Total correction of cardiac anomalies in infancy using extracorporeal circulation. Journal of Thoracic and Cardiovascular Surgery, 62, 117-124.

Dawes, G. S. (1968). Fetal and Neonatal Physiology, pp. 141-159. Year Book Medical Publishers: Chicago.

Di Eusanio, G., Ray, S. C., Donnelly, R. J., and Hamilton, D. I. (1979). Open heart surgery in the first year of life using profound hypothermia (core cooling) and circulatory arrest. British Heart Journal (in press).

Dobbing, J. (1974). Later development of the brain and its vulnerability. In Scientific Foundations of Paediatrics, pp. 565-576. Edited by J. A. Davies and J. Dobbing. Heinemann: London.

Gilman, S. (1965). Cerebral disorders after open heart operation. New England Journal of Medicine, 272, 489-498.

Hägerdal, M., Harp, J., Nilsson, L., and Siesjö, B. K. (1975). The effect of induced hypothermia upon oxygen consumption in the brain. Journal of Neurochemistry, 24, 311-316.

Haka-Ikse, K., Blackwood, M. J. A., and Steward, D. J. (1978). Psychomotor development in infants and children after profound hypothermia during surgery for congenital heart disease. Developmental Medicine and Child Neurology, 20, 62-70.

Hallman, G. L., and Cooley, D. A. (1971). Cardiovascular surgery in newborn infants. Results in 1050 patients less than one year old. Annals of Surgery, 173, 1007-1012.

Hamilton, D. I., Shackleton, J., Jackson Rees, G., and Abbott, T. (1973). Experience with deep hypothermia in infancy using core cooling. In Heart Disease in Infancy, pp. 52-58. Edited by B. G. Barratt-Boyes, J. M. Neutze, and E. A. Harris. Churchill Livingstone: Edinburgh.

Harris, E. A. (1973). Metabolic aspects of profound hypothermia. In Heart Disease in Infancy, pp. 65-74. Edited by B. G. Barratt-Boyes, J. M. Neutze, and E. A. Harris. Churchill Livingstone: Edinburgh.

Hikasa, Y., Shirotani, H., Satomura, K., Muraoka, R., Abe, K., Tsuchimi, K., Yokota, Y., Miki, S., Kawai, J., Mori, A., Okamoto, Y., Koie, H., Ban, T., Kanzaki, Y., Yokota, M., Mori, C., Kamiya, Y., Tamura, T., Nishii, A., and Asawa, Y. (1967). Open heart surgery in infants with an aid of hypothermic anaesthesia. Archiv für japanische Chirurgie, 36, 495-508.

Javid, H., Tufo, H. M., Najafi, H., Dye, W. S., Hunter, J. A., and Julian, O. C. (1969). Neurological abnormalities following open-heart surgery. Journal of Thoracic and Cardiovascular Surgery, 58, 502-509.

Lassen, N. A. (1974). Control of cerebral circulation in health and disease. Circulation Research, 34, 749-760.

Linde, L., Rasof, B., and Dunn, O. (1967). Mental development in congenital heart disease. Journal of Pediatrics, 71, 198-203. 


\section{Dickinson and Sambrooks}

Messmer, B. J., Schallberger, U., Galliker, R., and Senning, A. (1976). Psychomotor and intellectual development after deep hypothermia and circulatory arrest in early infancy. Journal of Thoracic and Cardiovascular Surgery, 72, 495-502.

Mohri, H., Dillard, D. H., Crawford, E. W., Martin, W. E., and Merendino, K. A. (1969). Method of surface-induced deep hypothermia for open heart surgery in infants. Journal of Thoracic and Cardiovascular Surgery, 58, 262-270.

Mori, A., Muraoka, R., Yokota, Y., Okamoto, Y., Ando, F., Fukumasu, H., Oku, H., Ikeda, M., Shirotani, H., and Hikasa, Y. (1972). Deep hypothermia combined with cardiopulmonary bypass for cardiac surgery in neonates and infants. Journal of Thoracic and Cardiovascular Surgery, 64, 422-429.

Rosomoff, H. L., and Holladay, D. A. (1954). Cerebral blood flow and cerebral oxygen consumption during hypothermia. American Journal of Physiology, 179, 85-88.

Silbert, A., Wolf, P. H., Mayer, B., Rosenthal, A., and Nadas, A. S. (1969). Cyanotic heart disease and psychological development. Pediatrics, 43, 192-200.

Stevenson, J. G., Stone, E. F., Dillard, D. H., and Morgan,
B. C. (1974). Intellectual development of children subjected to prolonged circulatory arrest during hypothermic open heart surgery in infancy. Circulation, 49 and 50, Supplement 2, 54-49.

Sugimura, S., and Starr, A. (1977). Cardiopulmonary bypass in infants under four months of age. Journal of Thoracic and Cardiovascular Surgery, 73, 894-899.

Sunderland, C. O., Matarazzo, R. G., Lees, M. H., Menashe, V. D., Bonchek, L. I., Rosenberg, J. A., and Starr, A. (1973). Total correction of tetralogy of Fallot in infancy. Circulation, 48, 398-405.

Venugopal, P., Olszowka, J., Wagner, H., Vlad, P., Lambert, E., and Subramanian, S. (1973). Early correction of congenital heart disease with surface-induced deep hypothermia and circulatory arrest. Journal of Thoracic and Cardiovascular Surgery, 66, 375-386.

Address for correspondence Dr D. F. Dickinson, Royal Liverpool Children's Hospital, Myrtle Street, Liverpool L7 7DG.

Received 13 April 1978 